\title{
Pengaruh Penggunaan ICT terhadap Peningkatan Kemampuan Memahami Teks Berbahasa Inggris dalam Pembelajaran Online
}

\author{
Erma Perwitasari \\ Program Studi Sistem Informasi Fakultas Teknologi Informasi Universitas Serang Raya \\ Jln. Raya Cilegon Serang KM. 5 - Taman Drangong Kota Serang \\ perwitasarierma@gmail.com
}

\begin{abstract}
Abstrak - Banyak pengajaran bahasa Inggris yang memanfaatkan Information Communication Technology (ICT) untuk menyelenggarakan pembelajaran online antara lain yang dilakukan di Edmodo, sebuah kelas virtual beralamat di http://www.edmodo.com. Tentu saja pengajaran secara online berbeda dari konvensional yang hanya diselenggarakan pada jadwal tertentu dengan menggunakan fasilitas ruang kelas, papan tulis, buku dan kertas.ICT pada virtual kelas memungkinkan pengajaran berlangsung setiap saat, tidak memerlukan fasilitas serupa di konvensional kelas. Penelitian ini bertujuan menganalisa pengaruh penggunaan Edmodo terhadap kemampuan mahasiswa memahami bacaan berbahasa Inggris selama dilakukan pembelajaran secara online. Metode penelitian ini berupa eksperimen semu dengan instrument penelitian berupa tes yang dilakukan terhadap sampel mahasiswa semester kelima Fakultas Ilmu Ekonomi di Universitas Serang Raya pada tahun akademik 2015-2016. Data yang diperoleh dianalisa dengan aplikasi statistik menggunakan Mann U Whitney test.Berdasarkan hasil analisis, interpretasi dan hasil penelitian, tidak ditemukan efek yang signifikan pada kemampuan mahasiswa dalam memahami bacaan berbahasa Inggris dalam pembelajaran online dan jika melakukan pengembangan teknik pembelajaran online, disarankan kepada pengajar untuk melakukan pertimbangan terhadap kemungkinan hambatan teknis yang berkaitan dengan penggunaan internet, kesiapan strategi pengajaran dan motivasi belajar mahasiswa.
\end{abstract}

Kata kunci: ICT, peningkatan kemampuan memahami bacaan berbahasa Inggris, pembelajaran online

\section{PENDAHULUAN}

Inovasi untuk pengembangan teknik pengajaran menggunakan teknologi komputer salah satunya adalah mediaLearning Management System (LMS) atau disebutVirtual Learning Environment (VLE) dan lebih dikenal sebagai kelas online.Media pembelajaran ini sangat menarik perhatian para pengajar karena fasilitas yang disediakan oleh kelas online memenuhi kebutuhan pengajar dalam menyampaikan materi, tugas, maupun quiz.Selain itu, mereka juga dapat mengembangkan materi ajar, melakukan penilaian dan feedback dengan cepat berkat hubungan internet yang digunakan pada online kelas ini.Online kelas yang banyak digunakan oleh pengajar diseluruh dunia tidak terkecuali oleh pengajar bahasa Inggris sebagai bahasa asing di Indonesia adalah Edmodo, yang beralamat di www.edmodo.com.

Pengajaran bahasa Inggris di tingkat universitas yang meliputi peningkatan empat keahlian bahasa juga dapat menggunakan media kelas online ini.Reading comprehension skill atau keahlian memahami bacaan berbahasa Inggris menjadi bagian dari pengajaran bahasa Inggris yang sangat penting di universitas.Hal ini karenamahasiswa harus mampu memahami isi tulisan di textbook, artikel di jurnal ilmiah dan sumber belajar lainnya yang berbahasa Inggris.Terlebih lagi, pada akhir masa studi mereka diwajibkan mempunyai sertifikat kompetensi pendamping ijazah, yaitu setifikat TOEFL.
Media kelas online menjadi alternatifuntuk dapat menyelenggarakan proses belajar kapanpun dibutuhkan. Sehingga, dengan keleluasaan itu, frekuensi belajar jadi lebih kerap sehingga mahasiswa dapat memenuhi kecukupan kosa kata dan pengetahuan tata bahasa (linguistic knowledge)selain latar belakang pengetahuan tentang topik bacaan (background knowledge) yang selama ini menjadi hambatan bagisebagian besar mahasiswa terutama di Serang, Banten dalam memahami bacaan berbahasa Inggris.

\section{METODOLOGI PENELITIAN}

Penelitian ini menggunakan metode quasi ekperimen dengan instrumenberupa tes yang diuji terlebih dahulu pada sesi tryout untuk memperoleh instrument tes yang valid dan reliable.Data kuantitatif pada penelitian adalah nilai hasil tes kemampuan membaca teks informasi berbahasa Inggris.Sampel penelitian dipilih dengan teknik cluster random sampling untuk memperolehgrup ekperimen dan grup control dari enam kelas mahasiswa semester lima di Fakultas Ekonomi Universitas Serang Raya.Kurun waktu penelitian adalahpada bulan April sampai dengan November 2015

Tabel 1 Variabel Penelitian

\begin{tabular}{|c|c|l|}
\hline \multicolumn{2}{|c|}{ Variable bebas } & Variable terikat \\
\hline \multicolumn{2}{|c|}{ Media Pembelajaran } & Kemampuan memahami bacaan \\
\cline { 1 - 2 } $\begin{array}{c}\text { Edmodo } \\
\text { (X1) }\end{array}$ & Konvensional & bahasa Inggris \\
(X2) & $(Y)$ \\
\hline
\end{tabular}


Grup eksperimen (X1) mendapatkan pengajaran di kelas online yang difasilitasi Edmodo, sedangkan kelas control (X2) mendapatkan pengajaran di kelas konvesional dengan fasilitas kelas yang disediakan oleh Fakultas Ekonomi di Universitas Serang Raya, antara lain: ruang kelas, infokus, whiteboard, kursi dan meja yang disesuaikan dengan jadwal pengajaran fakultas. Masing masing grup mendapat materi pengajaran dan periode belajar yang sama yaitu yang berkaitan Reading Comprehension on TOEFL texts selama 4 minggu.

Instrumen penelitan yaitu tes kemampuan membaca teks informasi dibuat untuk menguji kemampuan mahasiswa dalam memahami arti kata (vocabulary knowledge) dan kemampuan memahami bacaan berdasarkan struktur bacaan. Tes dirancang berupa soal pilihan ganda sejumlah 25 soal, untuk menguji kemampuan membaca teks bahasa Inggris berdasarkan beberapa indikator pada tabel berikut ini.

Tabel 2 Aspek dan Indikator Tes

\begin{tabular}{|c|l|}
\hline Aspek Uji & \multicolumn{1}{|c|}{ Indikator } \\
\hline \multirow{2}{*}{$\begin{array}{c}\text { Pemaha } \\
\text { man Arti }\end{array}$ Kata } & Mampu memahami arti kata berdasarkan context clues \\
\cline { 2 - 3 } & Mampu memahami arti kata berdasarkan structural clues \\
\cline { 2 - 2 } & Mampu memahami arti kata berdasarkan word-parts \\
\cline { 2 - 2 } Pemaha & Mampu memahami topik dan main idea \\
\cline { 2 - 2 } man Teks & Mampu menemukan informasi pada details \\
\cline { 2 - 3 } & Mampu membuat inference dari supporting details \\
\cline { 2 - 3 } & Mampu membuat transitional paragraph \\
\cline { 2 - 2 } & Mampu menemukan reference \\
\hline
\end{tabular}
(diadaptasi dari Janet Elder, 2007)

Instrumen penelitian diuji validitas dan reliabilitasnya dengan melakukan tryout yang diikuti oleh mahasiswa R2 (kelas malam) semester lima di Fakultas Ekonomi Universitas Serang Raya. Hasil uji tersebut dimenunjukkan bahwa total soal yang semula 50 hanya tersisa 25 soal yang valid dan reliable untuk digunakan sebagai instrument penelitian.

Data yang diperoleh dari pemakaian instrument penelitian ini adalah nilai berupa nilai angka.Setiap jawaban yang benar diberi nilai 1 dengan bobot nilai sebesar 20.Jawaban yang salah diberi nilai 0 dengan bobot nilai 0 .

Secara statistic, hipotesis yang akan diuji adalah sebagai berikut.

$$
\begin{aligned}
& \mathrm{Ho}=\mu 1.0 \leq \mu 2.0 \\
& \mathrm{H} 1=\mu 1.0>\mu 2.0
\end{aligned}
$$

Keterangan:

$\mathrm{H} 0=$ hipotesis null

$\mathrm{H} 1=$ hipotesis alternative

$\mu 1.0=$ median dari nilai tes reading milik mahasiswa yang diajar menggunakan Edmodo.

$\mu 2.0=$ median dari nilai tes reading milik mahasiswa yang diajar menggunakn media konvensional.

Tabel 3 Perbedaan Perlakuan pada Grup Kontrol dan

$$
\text { Grup Eksperimen }
$$

\begin{tabular}{|c|c|c|}
\hline Perlakuan & Grup Kontrol & Grup Eksperimen \\
\hline Teks & Media kertas & Softfilesdi Edmodo \\
\hline Sumber & Tidak ada & links unduhanditempel di \\
multimedia & & Edmodo \\
\hline Dosen & Tatap muka & $\begin{array}{c}\text { Instruksi secara online di } \\
\text { perkuliahan di kelas }\end{array}$ \\
\hline
\end{tabular}

\begin{tabular}{|c|c|c|}
\hline Perlakuan & Grup Kontrol & Grup Eksperimen \\
\hline Diskusi & Tatap muka & Diskusi secara online di \\
& perkuliahan di kelas & Edmodo \\
\hline Tugas dan & Tatap muka & Diberikan dan dikirimkan \\
Quiz & perkuliahan di kelas & secara online \\
\hline \multicolumn{2}{|c|}{ (diadaptasi dari Anna Ya Ni, 2013) }
\end{tabular}

\section{HASIL DAN PEMBAHASAN}

Data X1 diperoleh dari hasil tes kemampuan memahami teks berbahasa Inggris yang dikerjakan oleh mahasiswa yang mendapat pengajaran di online mediaEdmodo. Sebanyak 30 mahasiswa menjadi sample di kelas eksperimen ini. Beberapa tabel berikut ini berisi informasi tentang mean, median, mode, standar deviation, and standard error of mean.

Table 4 Diskripsi Statistik Data X1

\begin{tabular}{|l|r|}
\hline N $\quad$ Valid & 30 \\
Mean & 0 \\
Std. Error of Mean & $\underline{63.20}$ \\
Median & $\underline{2.429}$ \\
Mode & $\underline{60.00}$ \\
Std. Deviation & $\underline{80}$ \\
Variance & $\underline{13.304}$ \\
Skewness & .067 \\
Std. Error of Skewness & .427 \\
Kurtosis & -.996 \\
Std. Error of Kurtosis & .833 \\
Range & 48 \\
Minimum & $\underline{40}$ \\
Maximum & $\underline{88}$ \\
Sum & 1896 \\
\hline
\end{tabular}

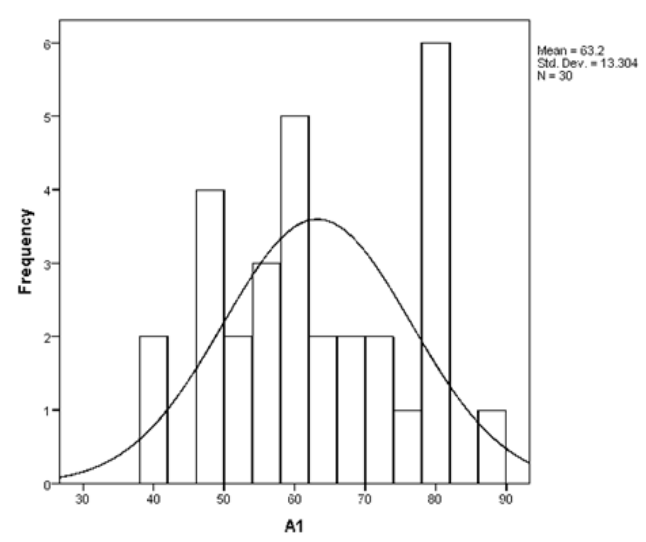

Gambar 1 Grafik kemampuan memahami teks berbahasa Inggris oleh mahasiswa yang diajar di Edmodo.

Table 5 Diskripsi Statistik Data X2

\begin{tabular}{|l|r|}
\hline N Valid & 30 \\
Mean & 0 \\
Std. Error of Mean & $\underline{58.93}$ \\
Median & $\underline{2.691}$ \\
Mode & $\underline{64.00}$ \\
Std. Deviation & $\underline{72}$ \\
Variance & $\underline{14.741}$ \\
Skewness & $\underline{.906}$ \\
Std. Error of Skewness & .427 \\
Kurtosis & .210 \\
Std. Error of Kurtosis & .833
\end{tabular}




\begin{tabular}{|l|r|} 
Range & 60 \\
Minimum & 20 \\
Maximum & 80 \\
Sum & 1768 \\
\hline
\end{tabular}

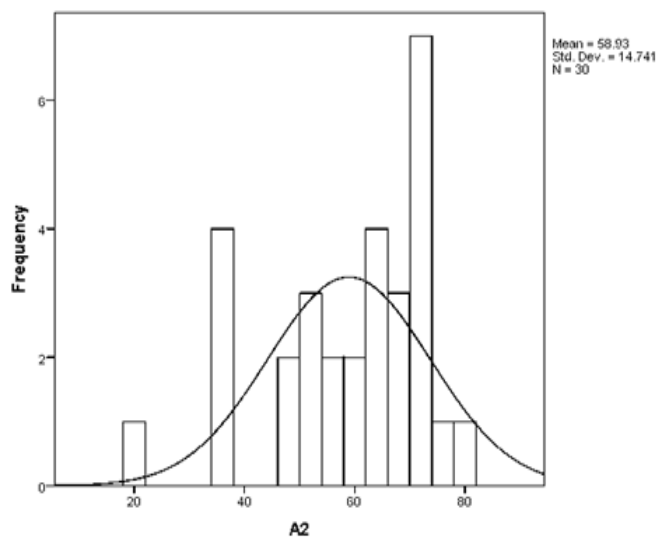

Gambar 2 Grafik kemampuan memahami teks berbahasa Inggris oleh mahasiswa yang diajar di kelas konvensional

Untuk mengetahui apakah pemahaman teks berbahasa Inggris yang dimiliki mahasiswa di kelas online berbeda secara signifikan dengan mereka yang di kelas konvensional, diujilah normalitas dan homogenitas data X1 dan X2 seperti terlihat pada tabel berikut ini.

Table 6 Uji Normalitas Data X1 dan X2

\begin{tabular}{|l|l|l|l|l|l|l|l|}
\hline \multirow{2}{*}{} & \multirow{2}{*}{ media } & \multicolumn{3}{|c|}{ Kolmogorov-Smirnov } & \multicolumn{3}{|c|}{ Shapiro-Wilk } \\
\cline { 3 - 8 } & & Statistic & df & Sig. & $\begin{array}{c}\text { Statist } \\
\text { ic }\end{array}$ & df & Sig. \\
\hline reading & 1 & .130 & 30 & $\frac{.200 *}{.949}$ & 30 & .159 \\
comprehension & 2 & .168 & 30 & $\underline{.031}$ & .909 & 30 & .014 \\
\hline *This is a lower bound of the true significance. \\
\hline
\end{tabular}

Hasil yang terlihat, bahwa semua data X1 terdistribusi normal ( sign. $=0.20>0.05)$ tetapi data X2 tidak terdistribusi normal (sig. $=0.031<0.05)$.

Tabel 7 Uji Homoginitas Varians Data X1 dan X2

\begin{tabular}{|c|c|c|c|c|c|}
\hline & & $\begin{array}{c}\text { Levene } \\
\text { Statistic }\end{array}$ & df1 & df2 & Sig. \\
\hline \multirow{4}{*}{$\begin{array}{l}\text { reading } \\
\text { compre } \\
\text { hension }\end{array}$} & $\begin{array}{l}\text { Based on } \\
\text { Mean }\end{array}$ & .163 & 1 & 58 & .688 \\
\hline & $\begin{array}{l}\text { Based on } \\
\text { Median }\end{array}$ & .050 & 1 & 58 & .824 \\
\hline & $\begin{array}{l}\text { Based on } \\
\text { Median } \\
\text { and with } \\
\text { adjusted } \\
\text { df }\end{array}$ & .050 & 1 & 54.441 & .824 \\
\hline & $\begin{array}{l}\text { Based on } \\
\text { trimmed } \\
\text { mean }\end{array}$ & .101 & 1 & 58 & .752 \\
\hline
\end{tabular}

Terbukti pula kedua data X1 dan X2 bersifat homogen, dimana sig. $=0.688>0.05$. Maka hipotesis yang dibuat akan di uji dengan Non Parametrik Tes, menggunakan MannWhitney U Test. Hasil tes seperti terlihat di tabel berikut ini.
Table 8 Mann-Whitney U Test of Hypothesis

\begin{tabular}{|l|l|l|c|c|}
\hline & media & N & $\begin{array}{c}\text { Mean } \\
\text { Rank }\end{array}$ & Sum of Ranks \\
\hline \multirow{2}{*}{$\begin{array}{l}\text { reading } \\
\text { compre } \\
\text { hension }\end{array}$} & 1 & 30 & 32.32 & 969.50 \\
\cline { 2 - 5 } & 2 & 30 & 28.68 & 860.50 \\
\hline
\end{tabular}

\begin{tabular}{|l|r|}
\hline & reading comprehension \\
\hline Mann-Whitney U & 395.500 \\
\hline Wilcoxon W & 860.500 \\
\hline Z & -.810 \\
\hline Asymp. Sig. (2-tailed) & .418 \\
\hline \multicolumn{2}{|l|}{ Grouping Variable: media } \\
\hline
\end{tabular}

Berdasarkan hasil yang terlihat di tabel tersebut diatas, meskipun nilai rata rata pemahaman teks ber bahasa Inggris pada mahasiswa di kelas online Edmodo (yaitu 32.32) lebih tinggi dari mereka yang di kelas konvensional (yaitu 28.68), perbedaan diantara keduanya dinyatakan tidak signifikan karena Asymp. Sig.(2-tailed $)=0.418>0.05$. Maka hasil uji hipotesis menggugurkan $\mathrm{H} 1=\mu 1.0>\mu 2.0$ tapi menerima $\mathrm{Ho}=\mu 1.0 \leq \mu 2.0$. Artinya, tidak ada perbedaan signifikan atas kemampuan memahami teks berbahasa Inggris pada mahasiswa yang diajar memakai online kelas di Edmodo dengan mereka yang diajar menggunakan media konvensional.

\section{KESIMPULAN}

Pengaruh penggunaan ICT berupa kelas online diEdmodo tidak signifikan dibandingkan dengan penggunaan media konvensional.Maka, penggunaan ICT berupa kelas online tidak dapat diunggulkan untuk menggantikan media konvensional dalam memberikan pengaruh pada peningkatan kemampuan memahami teks berbahasa Inggris pada mahasiswa.

Berdasarkan kesimpulan diatas, untuk meningkatkan kemampuan memahami teks berbahasa Inggris dengan menggunakan ICT berupa kelas online, disarankan antara lain:

1. Pilih mediapembelajaran online yang userfriendly untuk mengurangi kendala teknis ketika digunakan.

2. Dosen/pengajar yang menggunakan media online harus selalu memotivasi mahasiswanya untuk menjadiindependent learner dan mau berkolaborasi selama proses belajar berlangsung di kelas online.

3. Karena media online ini digunakan untuk pengajaran $E F L$ (English as Foreign Language) khususnya pada keahlian membaca teks, sebaiknya tidak dihindari melakukan switching language antara bahasa Inggris dan bahasa Indonesiaselama mengajar dan berdiskusi. Hal ini diharapkan dapat mengurangi hambatan berkomunikasi sehingga tujuan pengajaran tercapai dengan baik.

4. Penelitian lebih lanjut sebaiknya dilakukan dengan menambahkan variabel yang berkaitan dengan peran mahasiswa dan dosen sebagai pengguna media pembelajaran online ini. 


\section{REFERENSI}

[1] Alderson, J. Charles. (2000). Assessing Reading. Cambridge: Cambridge University Press

[2] Alyousef, H. S. (2005). Teaching Reading Comprehension to ESL/EFL Learners.The Reading Matrix, 5(2), pp. 143-154

[3] Anderson, Mark. (2003). Text Types in English 2. South Yarra: Macmillan

[4] August, D. \& T. Shanahan, T. (Eds.) (2006).Developing Literacy in Second Language Learners: Report of the National Literacy Panel on Language-Minority Children and Youth.Mahwah, $\mathrm{Nj}$ : Erlbaum

[5] Bates, A.W. (2002).Managing Technological Change: Strategies for College and University Leaders. San Francisco: Jossey-Bass

[6] Betts, Ben. (2014). Towards a Method of Improving Participation in Online Collaborative Learning: Curat. In Brian Sutton and Anthony 'Skip' Basiel, (Eds.), Teaching and Learning Online, New models of learning for Connected World. NY: Routledge. Retrieved from http://www.ewidgetsonline.net/dxreader/Reader.aspx?to $k e n=e 616909 c 9 a f 442 e e b$

[7] Brown, H Douglas. (2007). Principle of Language Learning and Teaching ( $5^{\text {th }} \mathrm{ed}$.). NY: Pearson Education Inc

[8] Carlson, Ginger and Raphael, Raphael. (2015). Let's Get Social: the Educator's Guide to Edmodo. Viginia: International Society for Technology in Education

[9] Elder, Janet. (2007). Entryways into College Reading and Learning. New York: Mc Graw-Hill

[10] Hrastinski, S. (2008).Asynchronous \& synchronous elearning. EDUCAUSE Quarterly, 31(4), pp. 51-55. Retrieved

from http://net.educause.edu/ir/library/pdf/eqm0848.pdf

[11] Lems, Kristin. (2010). Teaching Reading to English Language Learners: Insights from Linguistics. NY: The Guilford Press.
[12] Mason, Robin and Rennie, Frank. (2006). E-learning. The Key Concepts. London, NY: Roudledge.

[13] Mills, Steven C. (2006).Using The Internet for Active Teaching and Learning ( $1^{\text {st }}$ ed.). New Jersey: Pearson

[14] Nation, I.S.P. (2009). Teaching ESL/EFL Reading Writing.NY: Routledge

[15] Ni, Anna Yani. (2013). Comparing the Effectiveness of Classroom and Online Learning: Teaching Research Methods. Journal of Public Affair Education 19 (2), pp. 199-215. Retrieved from http://www.naspaa.org/jpaemessenger/Article/VOL192/03_Ni.pdf

[16] Nunan, David. (2003). Collaborative Language Learning and Teaching. Cambridge: Cambridge University Press.

[17] Oliver, R. (2001). Assuring the Quality of Oneline Learning in Australian Higher Education.In M.Wallace, A. Ellis \& D. Newton (Eds).Proceedings of Moving Online II Conference (pp. 222-231). Lismore: Southern Cross University

[18] Palloff , Rena M. and Pratt, Keith. (2007). Building Online Learning Communities: Effective Strategy for the Virtual Classroom, in Building Learning Communities in Cyberspace $\left(2^{\text {nd }}\right.$ ed.). San Fransisco: Jossey Bass.

[19] Pino-Silva, Juan. (2006). Extensive Reading through the internet: is it worth the while? The reading Matrix Vol. 6, No. 1, April (2006). Retrieved from

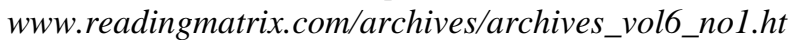
$m l$

[20] Zen, Deqi. (2008).How to Be an Effective Online Instructor? Paper presented at the $42^{\text {nd }}$ Annual TESOL Convention, New York, USA, April 2-5, 2008. Retrieved from http://eric.ed.gov/../ED502683.pdf 